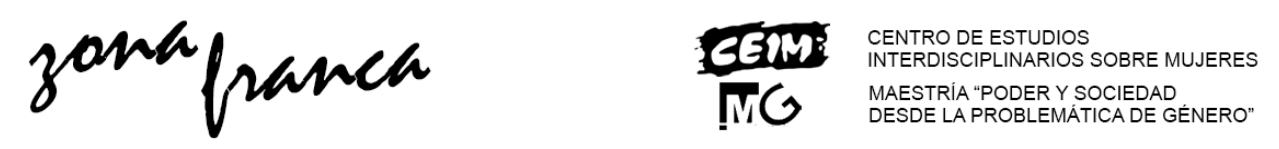

\title{
Crear familia: Diana Bellessi y la traducción
}

Laura L. García*

\section{Resumen}

El trabajo se propone analizar la figura de Diana Bellessi como traductora y el modo en que sus traducciones participan en su obra poética a partir de dos episodios de traducción. El primero se vincula con las poetas chinas traducidas al inglés por Ling Chung y Kenneth Rexroth en The Orchid Boat. Women Poets of China (1972), que Bellessi retraduce, reescribe y homenajea en la primera parte de Tributo del mudo (1982), y a través de las cuales encuentra una forma renovada de mirar la naturaleza del Delta. El segundo momento, vinculado a la escritura erótica, surge a partir de los poemas de Olga Broumas y Marichiko (heterónimo de Kenneth Rexroth) publicados y traducidos en Diario de poesía. A través de estas lecturas y traducciones, Bellessi abrir una senda inexplorada en la poesía escrita por mujeres en Argentina que culminará con la publicación Eroica (1988).

Palabras clave: paisaje - erotismo - poesía china - feminismo traducción

\section{Making family: Diana Bellessi and translation}

\section{Abstract}

The aim of the paper is to analyze the figure of Diana Bellessi as a translator and the way in which her translations interact with her poetic work in two moments.

*Universidad de Buenos Aires - Facultad de Filosofía y Letras. Contacto: laura.lucilag@gmail.com

García, Laura. "Crear familia: Diana Bellessi y la traducción” en Zona Franca. Revista del Centro de estudios Interdisciplinario sobre las Mujeres, y de la Maestría poder y sociedad desde la problemática de Género, №28, 2020 pp. 436-455. ISSN, 2545-6504 Recibido: 31 de junio 2020; Aceptado: 10 de noviembre 2020

Revista Zona Franca- Centro de estudios interdisciplinario sobre las mujeres (CEIM)- Maestría poder y sociedad desde la problemática de género (MG), Rosario, Argentina. ISSN, 2545-6504 http://zonafranca.unr.edu.ar/index.php/ZonaFrancal Número 28 (2020). 
The first one is related to the Chinese poets translated into English by Ling Chung and Kenneth Rexroth in The Orchid Boat. Women Poets of China (1972), which Bellessi retranslates, rewrites and pays homage to in Tributo del mudo (1982), where a new way of looking at the nature of the Delta is found through these readings and translations. The second moment, related to erotic writing, arises with the poems of Olga Broumas and Marichiko (heteronymous of Kenneth Rexroth) translated by Bellessi and published in Diario de poesía. Through these readings and translations, Bellessi opens an unexplored path in the poetry written by women in Argentina, which reaches its highest point with the publication of Eroica (1988)

\section{Keywords: Iandscape - eroticism - Chinese poetry - Feminism - translation}

A principios de los setenta, Diana Bellessi emprendió un viaje por el continente americano que culminó en Estados Unidos, país al que llegó con una canción de Bob Dylan como único conocimiento del inglés. Su relato del tiempo que vivió allí es principalmente el del descubrimiento de un universo sonoro y la entrega a la escucha de voces ajenas, en particular las de las mujeres afroamericanas y latinas, que hablaban en un inglés "que podía incorporar afectivamente y disfrutar" (Bellessi 2011: 103). En Nueva York, trabajó en una fábrica metalúrgica, donde su inglés se volvió más vivo en la convivencia con otras trabajadoras explotadas en el corazón del imperio: "Hermosas somos. Doscientas mujeres fuertes haciéndonos el día todo el día. Puertorriqueñas, negras, latinas ilegales: fruta madura, carne del tercer mundo" (1975:48). Por las noches, aprendía de manera autodidacta traduciendo poemas: "acompañada de un pequeño diccionario y un manual de gramática elemental, construía mi inglés letrado" (104).

Todo ocurre prácticamente de manera simultánea: el viaje, el aprendizaje de la lengua extrajera, el descubrimiento de voces nuevas en la fábrica, en la poesía y también en las calles, donde se encontró con las primeras movilizaciones del feminismo lesbianol en Estados Unidos. El encuentro con esa multiplicidad de voces y experiencias terminan por hacer de Bellessi una traductora, pues es entonces

\footnotetext{
I Ante la pregunta por sus estudios feministas en Estados Unidos, Bellessi responde: “¿Qué estudios feministas? Yo iba a la plaza con las locas que iban a la plaza... He leído parte de eso, de los estudios de género, pero nunca me ha afectado demasiado. No me interesan" (Francese, 2017).
}

Revista Zona Franca- Centro de estudios interdisciplinario sobre las mujeres (CEIM)- Maestría poder y sociedad desde la problemática de género (MG), Rosario, Argentina. ISSN, 2545-6504 http://zonafranca.unr.edu.ar/index.php/ZonaFranca| Número 28 (2020). Página 437 
cuando empieza a traducir poemas de Denise Levertov, June Jordan, Muriel Rukeyser y Adrienne Rich, entre otras: "las traducía para entenderlas mejor. En realidad, fueron traducciones de lectura, muchos años después, cuando ya tenía un archivo importante, me pareció que podía armar una antología" (Bellessi,2017: 88). Así, en 1984 publica Contéstame, baila mi danza, una antología de poetas estadounidenses que se fue ampliando con el paso del tiempo" y a la cual Bellessi llama su "comarca de traducción" formada exclusivamente por autoras mujeres (2017: 88).

El inicio de su tarea como traductora no puede pensarse fuera del encuentro con el feminismo: "En una tradición abrumadoramente mayoritaria de varones, quería crear familia y linaje, quería oír las voces de las mujeres" (2017: 105). Este inicio no se relaciona en absoluto con la constitución de una figura letrada, sino con una experiencia concreta (la del viaje y la vida en el extranjero), una necesidad literaria (la búsqueda y la creación de nuevos parentescos literarios) y política (la vinculación al feminismo), que dan lugar a la figura de la aventurera y la pionera. En la época anterior a su viaje, antes de 1972, en la Argentina no se hablaba de feminismo, y a su regreso, cuando apenas estaban asomando la cabeza los movimientos feministas, se impuso la dictadura militar: "Me sentí hablando sola con las paredes, no tenía casi con quién hablar, y cuando lo hacía con algunas amigas, me miraban como si yo estuviera loca" (2017: 66). Fue recién en la década del ochenta que resurgió "un cierto feminismo de base", comenzaron los encuentros feministas y se abrieron nuevos espacios de circulación, difusión y debate.

Junto con su poesía y sus ensayos (publicados a lo largo de la década del ochenta principalmente en Feminaria y compilados en Lo propio y lo ajeno en 1996), sus traducciones formaron parte insoslayable de la creación de ese espacio emergente para la escritura producida por mujeres en la década del ochenta. La traducción fue esencial para la construcción de ese espacio, puesto que con ella se

\footnotetext{
" Hubo una segunda edición en 1995, donde se amplió la cantidad de poetas a diez, y una tercera en 2019, que incluye a trece poetas.
}

Revista Zona Franca- Centro de estudios interdisciplinario sobre las mujeres (CEIM)- Maestría poder y sociedad desde la problemática de género (MG), Rosario, Argentina. ISSN, 2545-6504 http://zonafranca.unr.edu.ar/index.php/ZonaFranca| Número 28 (2020). 
introducen modelos, procedimientos y posibilidades previamente inexistentes en la cultura vernácula (Willson, 2004: 33). Cabe destacar, en este sentido, el trabajo compartido con Mirta Rosenberg en Diario de Poesía, donde ambas (únicas figuras femeninas de la revista) publicaron un sinnúmero de traducciones y notas destinadas a la ampliación y la difusión del campo de la escritura de mujeres y propiciaron "lo que ellas mismas reclamaban desde su ensayística: la construcción de una tradición de poesía escrita por mujeres con la cual dialogar e interactuar para la constitución de una poética propia" (Mallol, 2013: 3).

El viaje de formación siempre fue un ritual de pasaje para la intelectualidad latinoamericana, y en el siglo el XIX dio lugar a la figura, según la transposición que hace Willson del concepto de Viñas (2019: 87), de los "gentlemen-traductores" o, más precisamente "gentlemen-importadores", quienes, a través de la importación de cultura extranjera, procuraron constituir una literatura nacional. A través de Rubén Darío, Caresani opone a este modelo la figura del traductor portador, que no pretende construir nación, sino que desestabiliza la organicidad, "degenera el 'cuerpo' nacional o en-rarece la ciudad letrada" (2015: 10). Por fuera de estos modelos que dependen de una ubicación privilegiada en la cultura de origen y se definen ya por su servicio, ya por su oposición a lo nacional, el siglo xx trae otras figuras traductoras.

A través de la delimitación de un territorio propio creado a partir de una incorporación afectiva de lo ajeno'"I, Bellessi propone el campo de sus traducciones como comarca, donde las relaciones no se dan entre culturas nacionales, sino entre alteridades en diálogo. Toda su obra (poesía, ensayos y traducciones) se caracteriza por una búsqueda de re-afectivización del mundo a través de una voz que se tiende hacia lo otro. La traducción es así "una extraña eucaristía", un acto de "comunión" (Bellessi, 2011: 115). Su figura no es ya la de la importadora que

III Esa política de la afectividad se advierte, por ejemplo, en el vínculo estrecho que establecen Bellessi y Ursula K. Le Guin a través de una profusa correspondencia. Uno de los frutos de esa amorosa relación es el libro de traducciones mutuas Las gemelas del sueño/ The Twins the Dream.

Revista Zona Franca- Centro de estudios interdisciplinario sobre las mujeres (CEIM)- Maestría poder y sociedad desde la problemática de género (MG), Rosario, Argentina. ISSN, 2545-6504 http://zonafranca.unr.edu.ar/index.php/ZonaFrancal Número 28 (2020). 
engrosa las bibliotecas nacionales ni la de portadora de un corpus extraño que enrarece el cuerpo nacional, sino la de quien, en un ámbito mayoritariamente masculino, crea "familia y linaje" a través de parentescos novedosos, no solo por la diferencia en la adscripción genérica de la firma, sino por el modo de relación: "ni adoración repetitiva de los antepasados ni parricidio" (Bellessi, 1986: 27), es decir, lejos de la nociones de tradición y ruptura que caracterizan la estructura edípica y patrilineal de las historias literarias (Pollock, 2002).

Si bien es cierto que "una teoría de la traducción implica necesariamente una concepción de la lengua y la cultura que se habita" (Panesi, 2000:84), cabe ir un paso más atrás para señalar que toda traducción implica necesariamente una teoría de la traducción. Traducir, en este caso, es un modo de crear nuevos parentescos para poder escribir en ese campo nuevo que era el de las escrituras producidas por mujeres en los ochenta. En el caso de Bellessi, se trata de un impulso traductor que se originó en un momento preciso: el viaje a Estados Unidos, el encuentro con el feminismo y la poesía angloparlante escrita por mujeres. Posteriormente, Bellessi perdió el interés en el feminismo como potencia política; no obstante, el impulso traductor y la huella que dejó en el campo cultural continúa hasta el presente ${ }^{\mathrm{IV}}$.

\section{Traducir para romper el silencio: Tributo del mudo}

En 1982, Diana Bellessi publica su segundo libro, Tributo del mudo, resultado de un momento de retracción entre dos momentos expansivos de su trayectoria. Antes de la intensa actividad como traductora, poeta y ensayista en la década del

\footnotetext{
IV "Hay un momento extraordinario que siempre se ve atravesar a cualquier mujer: el día en que se da cuenta de ser una mujer no es lo mismo que ser un varón, no es lo mismo frente a las leyes ni frente a la sociedad. Esto seguirá así hasta que desaparezcan las diferencias de género, y eso está muy lejos de suceder aún. Pero en lo referido al pensamiento, todo empezó a caer en la repetición, y aunque hubo ideas fundantes que fueron espléndidas, y en muchos sentidos lo siguen siendo, lo que vino después fue más lento y opaco... Llegó un momento en que me empecé a desinteresar del pensamiento feminista, creo que porque no hubo grandes progresos y porque me atraparon los movimientos del campo popular a fines de los 90 . Me volvió a parecer infinitamente más interesante la lucha de clases, aunque en la lucha de clases va inscripta también la pelea por la igualdad de las mujeres". (Bellessi, 2017: 66)
}

Revista Zona Franca- Centro de estudios interdisciplinario sobre las mujeres (CEIM)- Maestría poder y sociedad desde la problemática de género (MG), Rosario, Argentina. ISSN, 2545-6504 http://zonafranca.unr.edu.ar/index.php/ZonaFrancal Número 28 (2020). 
ochenta, Bellessi regresa al país en plena dictadura, se refugia en el Delta del Tigre y entre el 78 y el 79 escribe los poemas de este "libro de poemas breves, sacados como hilachas del silencio, porque desaparecieron los cuerpos y desaparecieron las voces" (Bellessi, 2017:10).

En la primera parte del libro, "Jade", la traducción constituye un recurso privilegiado. Bellessi encuentra un modo de romper el silencio a través del diálogo con las lejanas voces de un conjunto de poetas chinas de distintos períodos, desde la dinastía Tang hasta la dinastía Ch'ing, que ella lee en inglés en traducción de Kenneth Rexroth y la académica china Chung Ling en The Orchid Boat. Women poets of china (1972). Bellessi traduce desde el inglés en algunos de sus poemas, de manera implícita, y también de manera explícita en las citas que abren Tributo al mudo. En 1987, publica sus versiones de algunas de las traducciones que Rexroth y Chung hacen de la poeta Li Ch'ing-chao en Diario de Poesía. Así, el tributo es también un homenaje a Ixs traductores que propiciaron la alianza con estas voces compañeras ${ }^{v}$.

Tributo del mudo comienza con una serie de citas que provienen de The Orchid Boat. La primera es una traducción de una nota de Rexroth a un poema de Yü Hsüan-Chi (s. IX) y una retraducción del inglés de uno de sus poemas. Yü HsüanChi fue primero concubina y luego sacerdotisa taoístaVI. Como tal, recorrió toda

\footnotetext{
$\vee$ En palabras de Bellessi: "Las poetas chinas entraron a mi vida cuando yo era muy jovencita, cuando tenía diecisiete o dieciocho años. Entonces leía cuanta cosa encontraba, en inglés, italiano... Sobre todo, de la dinastía Tang y la dinastía Tsing. El paisaje del delta se parece mucho - y se parecía mucho más antes - a la naturaleza que se hace presente en la poesía china. Por eso Tributo del mudo también es un homenaje a las traducciones de poesía china, sobre todo las que hizo Kenneth Rexroth, donde se juntan ambos paisajes y donde se fabulan personajes que parecen mujeres chinas, pero que en realidad son personajes de aquí, del delta. Soñados, desde aquellas lecturas y experimentados, como diría Juan L., desde la tierra acuática de 'En el aura del sauce"' (Bellessi 2017: 10)

VI El taoísmo, sobre todo a partir de la dinastía Tang, les ofrecía a las mujeres la posibilidad de llevar una vida de relativa libertad: como sacerdotisas del Tao, podían viajar, leer, escribir y asociarse libremente. A diferencia de las monjas budistas, las sacerdotisas taoístas podían tener relaciones íntimas, pero no eran propiedad de nadie (Chung, 1972: 145). Por otra parte, las relaciones homosexuales entre mujeres (principio yin) no eran condenadas, puesto que se consideraba que la combinación yin-yin no provocaba desequilibrios, a diferencia de las relaciones homosexuales entre hombres (principio yang).
}

Revista Zona Franca- Centro de estudios interdisciplinario sobre las mujeres (CEIM)- Maestría poder y sociedad desde la problemática de género (MG), Rosario, Argentina. ISSN, 2545-6504 http://zonafranca.unr.edu.ar/index.php/ZonaFrancal Número 28 (2020). Página 441 
China y tuvo numerosos amantes, hasta que la acusaron de asesinato y la ejecutaron. En esta página, la transcripción de esa voz traducida coexiste con la voz de Bellessi, que comenta sobre la frescura de sus poemas en el presente: "sus hermosos poemas reposan / en la sombra del verano" (2009: 153).

Al mismo tiempo, la voz de Yü Hsüan-Chi, en tanto doblemente traducida, es una voz a tres voces: en ella conviven la poeta china, los traductores al inglés, la traductora al español. Aunque Bellessi no lo mencione en las referencias a las citas, las traducciones de The Orchid Boat son una colaboración entre Rexroth y Chung Ling, poeta, académica y traductora de origen cantonés, que además escribió un estudio sobre las mujeres en la poesía china que se incluye como epílogo de la antología. Así, Tributo del mudo se abre en esta primera página plagada de voces de autoridad y, paradójicamente, una voz muda, precisamente la de la mujer detrás del poeta célebre ${ }^{\mathrm{VII}}$.

Es posible pensar estas citas como transcripciones de los subrayados de Bellessi, cuyo acto de lectura se convierte en acto creativo y participativo, al incluir y, más aún, traducir esas lecturas. Hay una necesidad de distanciarse de las voces y los espacios familiares para poder volver con la mirada renovada, un alejamiento que funciona como cura de la voz a través lo ajeno. Volverse otra para volver a ser una, mirar lo propio con ojos ajenos para poder volver a habitarlo.

En la traducción se practica una y otra vez esa pérdida parcial del yo, pero también de lo otro, puesto que nada llega a la otra lengua intacto. Como señala De Man a propósito de "La tarea del traductor" de Walter Benjamin (en Szendy 2003: 74), la traducción deja expuesta una movilidad y una inestabilidad en el original que no es posible advertir antes del pasaje de una lengua a la otra. En ese pasaje se produce la pérdida, la transformación del que traduce y del traducido. Por otra parte,

VII Lo cierto es que Rexroth no tenía conocimiento del chino: "Como Pound, Rexroth logró memorizar varios cientos de caracteres chinos, pero nunca llegó a tener suficiente conocimiento del idioma para traducir directamente sin la ayuda de otros traductores. Como demostró Ling Chung, Rexroth tradujo la vasta mayoría de sus poemas a partir de fuentes inglesas o francesas sin haber consultado los poemas en chino" (Bradbury 2003: s/p., mi traducción)

Revista Zona Franca- Centro de estudios interdisciplinario sobre las mujeres (CEIM)- Maestría poder y sociedad desde la problemática de género (MG), Rosario, Argentina. ISSN, 2545-6504 http://zonafranca.unr.edu.ar/index.php/ZonaFranca| Número 28 (2020). Página 442 
la traducción es el resultado de un deseo de participar de lo que se lee, sin que esto implique un acto de violencia que borre al otro. Una delicada tensión entre ambos polos se mantiene siempre encendida en un tercer vértice de deseo que es el poema traducido, o metapoema, según la definición de James Holmes: "La traducción o metapoema es al poema lo que el poema es a la realidad" (citado en Willson, 2019: 29).

El río a la vera del cual se sientan todas estas poetas parece ser el mismo. Bellessi recoge los poemas que flotan hacia ella y la lectura transforma su mirada y su voz. "Jade" incluye diez poemas donde la lectura y retraducción de las poetas chinas se incorporan al texto propio. En los primeros cinco poemas, que homenajean a cinco de las poetas traducidas por Chung y Rexroth (Li Ch'ing-chao, Wu Tsao, Han Ts'ui P'in, Ch'ien T'ao y Wang Wei), se incluyen referencias a los poemas de las autoras al tiempo que se repiten ciertas figuras y tropos (la hoja que cae, la niebla, el grillo) que generan una continuidad entre el paisaje chino y el del Delta.

En los últimos cinco poemas, Bellessi vuelve la mirada sobre el Delta y sus personajes con fuerza renovada. Este resurgimiento va acompañado por la ética de una mirada que no se constituye a partir del dominio sobre lo que observa sino, sobre todo, como señala Monteleone, a partir de "una relación entre sujeto y objeto, donde no hay fijeza en ninguno de los polos. [...] la mirada, nombrada en el lenguaje, produce un tipo de saneamiento de la visión, una 'regeneración' del vínculo del sujeto con lo real" (2009: 18). Lo que no puede hablar, oye con atención: ante la desaparición del habla, Bellessi se vuelve receptiva al mundo circundante. Así, las lecturas y el paisaje forman parte de una misma realidad que entra por los ojos, no como instrumento servil que "decora el pensar, el sentir de su amo: quien la mira", sino que ingresa al poema como espacio imaginario, bajo la mirada inmanente "que coloca al yo del que escribe abierto en su vulnerabilidad, participante en la naturaleza, afectándola y afectado por ella -y este es quizás el misterio del diálogo, entra al espacio del detalle, de las pequeñas cosas" (Bellessi, 1996: 96).

Revista Zona Franca- Centro de estudios interdisciplinario sobre las mujeres (CEIM)- Maestría poder y sociedad desde la problemática de género (MG), Rosario, Argentina. ISSN, 2545-6504 http://zonafranca.unr.edu.ar/index.php/ZonaFrancal Número 28 (2020). 
La primera pieza de Jade, "Leyendo un poema de Li Ch'ing-Chao", señala ya desde el título la posición lectora desde la cual se escribe. El poema de misticismo erótico escrito por Li' Ch'ing Chao (1084-1151) y traducido por Rexroth y Chung bajo el título "To the Tune of 'The honor of a Fisherman"' se traslada al tono sutilmente voluptuoso del poema de Bellessi, donde el cuerpo es un bote que navega en un mar de arena, imagen que evoca el estancamiento de la voz. Al mismo tiempo, nos recuerda que la voz siempre encarna en un cuerpo que goza o padece en este mundo. Inmovilidad y movimiento son simultáneos (Ybáñez 2019: 3), como reflejo del principio taoísta según el cual en la más profunda quietud siempre hay movimiento. Los opuestos conviven y se complementan de manera necesaria. En el más profundo silencio también hay voces. Por otra parte, surge un nosotros: dos cuerpos que en medio del estancamiento en el mar de arena se encuentran y se enlazan hacia un futuro incierto: "por un largo camino / más allá del crepúsculo / van nuestros rostros enlazados" (2009: 155).

En el poema siguiente, "En una hoja púrpura", Bellessi dialoga con "A Poem Written on a Floating Red Leaf', de Han T'sui-p'in (s. IX). Allí, se replica una leyenda repetida en varios poemas tradicionales chinos, que cuenta la historia de un erudito que encontró un poema sobre una hoja flotando en el agua lindante a las tierras del palacio y más tarde se casó con la concubina liberada que reconoció el poema escrito en la hoja. En el poema de Bellessi, no es un hombre si no la poeta a la vera del Paraná quien, mientras escucha el canto del pato sirirí, encuentra un poema "liberado al azar del río, / para que alguien en el mundo de los hombres / lo recogiera" (2009: 156). El río se convierte de este modo en un río místico que irrumpe en el aislamiento e incita a escribir. De prisionera a prisionera transita la palabra que resurge con dificultad. Así, la continuidad entre la lectura y la escritura, por un lado, y entre espacios y tiempos distantes, por el otro, se establece a partir de la figura del río.

Wu Tsao (1799-1862) fue una poeta muy popular en su tiempo, cuyos poemas, según Sung-Rexroth, se cantaban en toda China. Antes de esto, Wu Tsao

Revista Zona Franca- Centro de estudios interdisciplinario sobre las mujeres (CEIM)- Maestría poder y sociedad desde la problemática de género (MG), Rosario, Argentina. ISSN, 2545-6504 http://zonafranca.unr.edu.ar/index.php/ZonaFranca| Número 28 (2020). 
padeció la opresión del concubinato hasta que se escapó en un bote y se convirtió en sacerdotisa taoísta. Bellessi escribe "A Wu Tsao", donde vuelve a poner en escena algunas imágenes de los poemas "For the Courtesan Ch'ing Lin" y "Returning from Flower Law Mountain on a Winter Day". El primero, es un elogio de los rasgos de la amada, que la traducción de Sung-Rexroth incorpora en la tradición de poemas líricos desde Safo en adelante. El poema de Bellessi se divide en dos partes. En la primera, el rostro la amada aparece en un sueño, iluminado. Los siguientes versos retoman estos de Wu Tsao: "Millions of years of decline lie ahead of us / As destruction turns into ashes" (Chung-Rexroth 1972: 76):

\author{
Millones de años a través de los cuales el universo \\ asciende y declina \\ y vos allí, \\ en tu vestido transparente de seda \\ viendo caer \\ las flores del ciruelo sobre la hierba
}

(Bellessi 2009:157)

La segunda parte del poema es una contemplación de la escena amorosa que describe Wu Tsao en su poema a la cortesana Ch'ing Lin, donde las amantes beben vino, se recitan los poemas y se pintan las cejas. La inclusión de Safo en el poema de Bellessi forma una red en la cual ella misma se inserta, de modo que Safo deja de ser la excepción en la larga historia de la poesía occidental y patrilineal. En "Homenaje a Ch'ien T'ao" Bellessi amplía un breve poema de esta poeta de principios del siglo XI, concubina de un primer ministro de la Dinastía Song, de quien solo sobrevivieron dos poemas. Uno de ellos es el que traducen Rexroth y Chung para su antología, "Written at a Party where my Lord Gave Away a Thousand Bolts of Silk":

Revista Zona Franca- Centro de estudios interdisciplinario sobre las mujeres (CEIM)- Maestría poder y sociedad desde la problemática de género (MG), Rosario, Argentina. ISSN, 2545-6504 http://zonafranca.unr.edu.ar/index.php/ZonaFrancal Número 28 (2020). 
A bolt of silk for each clear toned song.

Still these beauties do not think it is enough.

Little do they know of a weaving girl,

Sitting cold by her window,

Endlessly throwing her shuttle to and fro.

(Rexroth y Sung 1972: 76)

Bellessi reescribe este poema en primera persona con la voz de la tejedora de Ch'ien T'ao en su encierro, mientras le llegan rumores de la fiesta de su señor e intenta dilucidar los sonidos. En ese intento describe cuatro momentos, cuatro imágenes contundentes fraguadas en la oscuridad del cautiverio. El deseo de ver y tocar espolea la imaginación, que proyecta así todo aquello que no se ve: la imagen del banano bajo la lluvia, el picaflor ante los ojos del amado, las hojas del sauce que descienden sobre el sueño y el sol dorado sobre los tejados, mientras la concubina sigue entretejiendo los brocados con la pena del trabajo: "Otras vestirán sobre los hombros adorables / estas fatigadas, interminables / piezas de seda" (2009: 158).

Por último, en "A Wang Wei, viajando por un río de la China Central", aparece otra figura que contrasta con la servidumbre y el encierro de Ch'ien T'ao. Después de pasar por las prisiones del concubinato y el matrimonio, la poeta Wang Wei (s. XVII), al igual que Wu Tsao y Yü Hsüan-Chi, se convirtió en sacerdotisa taoísta y viajó en un pequeño bote con su biblioteca por los ríos de China Central. Bellessi celebra a esta "transparente viajera" que logró cambiar su vida:

A la proa de tu bajel,

aldea tras aldea

ves lavar a las mujeres

la pesada ropa

Revista Zona Franca- Centro de estudios interdisciplinario sobre las mujeres (CEIM)- Maestría poder y sociedad desde la problemática de género (MG), Rosario, Argentina. ISSN, 2545-6504 http://zonafranca.unr.edu.ar/index.php/ZonaFrancal Número 28 (2020). 
que el otoño prepara.

Cae una hoja

y es infinito su caer.

Polvo leve de los años

disperso en el vaivén

de una cuna en el agua.

(2009: 159)

El destino de Wang Wei ya no es el de las mujeres que lavan la ropa en el río sino el de quienes lo recorren. Sobre ese mismo bote en ese mismo río parece contemplarse a Felicitas en el poema siguiente, "Mirando a Felicitas lavar la ropa", donde se produce el pasaje de la China al Paraná: "Sobre las escaleras del muelle / como ramos de caña de ámbar / reposa la ropa lavada" (2009: 160). Así, en los siguientes poemas la mirada se va acercando cada vez más a lo propio y lo cercano, a las casuarinas, azucenas y fresnos que meditan en las cercanías y que, lejos de tener el carácter separado de "naturaleza" o "paisaje" que acompaña y emula la emoción de la poeta, coexisten con la voz poética en un espacio común. Cada uno de los cinco poemas que cierran "Jade" son como capturas de un momento de esas vidas, imágenes quietas que, no obstante, están en el perpetuo movimiento de todo lo que crece, muere y coexiste con otras especies.

En el último poema de "Jade", esa mirada que fue acercándose lentamente al paisaje circundante termina en una especie de zoom sobre la mesa donde se escribe, con la certeza de que es posible escribir y las manos entrelazadas con otras manos:

Puedo escribir poemas, lo sé,

con las voces y los días que cayeron

Revista Zona Franca- Centro de estudios interdisciplinario sobre las mujeres (CEIM)- Maestría poder y sociedad desde la problemática de género (MG), Rosario, Argentina. ISSN, 2545-6504 http://zonafranca.unr.edu.ar/index.php/ZonaFrancal Número 28 (2020). 
en el tobogán de sueño

de los años,

en esta rústica mesa de madera

donde reposan nuestras manos.

(2009: 164)

Así, después de la intercesión a esas voces lejanas y pasadas, es posible volver a escribir. En las siguientes secciones del poemario, Bellessi ahonda aún más en el presente opresivo que se yuxtapone con su realidad en el Delta. Cada sauce, cada pájaro, cada animal adquieren el color de la sangre y se convierten en significantes de una violencia que irrumpe en todas partes. Estas figuraciones de la violencia se cruzan con algunas exploraciones eróticas, un cruce que Bellessi indagará más hondamente en Eroica (1988), pero que ya comienza a esbozarse en lecturas y traducciones. Si Tributo del mudo rompe el silencio para para decir lo que está prohibido decir, Eroica da un paso más audaz y quiebra la Ley: "Altera el orden / la creación empieza" (Bellessi 2009: 423).

\section{El affair Marichiko}

En el segundo número de Diario de Poesía (primavera 1986), Bellessi publica la nota "Escrituras eróticas", donde se incluyen traducciones de Olga Broumas, poeta griega radicada en Estados Unidos, y Marichiko, seudónimo de una poeta japonesa contemporánea. Los poemas de Marichiko son retraducciones del inglés a partir de las versiones de Kenneth Rexroth, incluidas en su libro Morning Star.

En estas poetas, la mirada inmanente se vuelve sobre el cuerpo amado como paisaje, algo que Bellessi explorará más tarde en Eroica (1988). La escritura de Marichiko "juega simbólicamente [con] las pasiones sobre la escena del paisaje; más aún, del detalle de la naturaleza viva [...] Aquí, el cuerpo de la poeta y el de su objeto amoroso juegan como otros detalles en esa figura orgánica mayor que los

Revista Zona Franca- Centro de estudios interdisciplinario sobre las mujeres (CEIM)- Maestría poder y sociedad desde la problemática de género (MG), Rosario, Argentina. ISSN, 2545-6504 http://zonafranca.unr.edu.ar/index.php/ZonaFrancal Número 28 (2020). 
contiene" (1986: 26). Mientras que en el ciclo de poemas amorosos de Marichiko Bellessi encuentra la revelación del yo a través del cuerpo de la amante, en Broumas advierte la revelación de una simetría en el amor lesbiano: se ama lo mismo en la otra. Ya no se va de la naturaleza como "espejo de la amada" al cuerpo, sino que el cuerpo de la otra se convierte en paisaje, una elaboración que busca lo informe en un intento de "amorosa descolonización" (1986: 27).

Un año más tarde, en el número 6 de Diario de Poesía (primavera de 1987), Bellessi publica "Rexroth: poeta, traductor, falsificador", donde se revela que Marichiko no era un seudónimo de una poeta japonesa sino del propio Rexroth. La nota incluye también fragmentos de un ensayo de Eliot Weinberger (quien descubre, tras la muerte de Rexroth en 1982, que Marichiko es un heterónimo) y una serie de traducciones: nuevas traducciones de Marichiko, siete poemas de Rexroth y cuatro poemas de Li Ch'ing-chao a partir de las traducciones de Rexroth y Ling Chung publicadas en Li Ch'ing-chao. Complete poems (1979).

La hazaña de Rexroth consiste, según Bellessi, en haber logrado "textos hablados desde el cuerpo de una mujer, hablados desde el cuerpo de su amante cuyo género es señalado por el propio Rexroth como 'ambiguo'” (1987: 28). En efecto, Rexroth aclara en una nota sobre su autora inventada la ambigüedad del sexo del objeto amoroso. En lugar de mantener esta ambigüedad, Bellessi decide traducir el pronombre en femenino, una decisión que no solo es mucho más audaz que la sutil indeterminación que elige Rexroth, sino que también es una toma de posición. Si los ochenta fueron escenario de la emergencia de una cantidad notable de libros firmados por mujeres, que dejan de ser "una rareza, el tropiezo de una excepción" (Genovese, 2015: 15) y comienzan a participar en la cultura de forma cuantitativamente mayor, traducir y escribir poesía amorosa lesbiana en este contexto constituye un gesto radical.

Por otra parte, esta decisión se vincula con una concepción dialéctica de la temporalidad de las luchas políticas. Si el ser humano es fundamentalmente

Revista Zona Franca- Centro de estudios interdisciplinario sobre las mujeres (CEIM)- Maestría poder y sociedad desde la problemática de género (MG), Rosario, Argentina. ISSN, 2545-6504 http://zonafranca.unr.edu.ar/index.php/ZonaFrancal Número 28 (2020). 
andrógino, señala Bellessi, hasta que la miseria de la Historia dominada por la opresión ceda paso a esta "utopía resplandeciente", habrá que "atravesar dialécticamente los territorios de la antítesis: preguntarnos por la condición femenina, la específica opresión femenina, su mirada y su habla" (1987: 28). Así, Bellessi marca temporalidades en la lucha feminista y señala que para alcanzar la utopía de la ausencia de asignación de género primero hay que agotar las opresiones que alberga el binarismo. Se trata en parte de un aprendizaje que ocurre en la traducción, en ese momento de pasaje de una lengua a la otra que, a partir de este encuentro con lo otro, confronta a la traductora con lo propio: una "retórica del descubrimiento del yo a través del otro" (Balderston 2011: 340).

En los poemas de Broumas, los cuerpos se espacializan como territorio de descubrimiento y exploración, las vulvas son cuevas o puertas a catedrales rosadas que se vislumbran a través del espejo, las marcas en el cuerpo son fósiles del amor, los pezones se liban como frutas en un Edén reinventado y sin Adán, que contrasta con la rebelión que implica un beso entre dos mujeres en el medio hostil de la ciudad, donde "Tu beso / es para ellos / un signo de traición" (Bellessi, 1986:27). A diferencia de Marichiko, cuyo ciclo de poemas relata el surgimiento y la muerte de un amor romántico fiel a la tradición de la lírica amorosa, los poemas de Broumas desestabilizan el amor romántico y el objeto amoroso único sumando cuerpos al lecho. Comienzos y rupturas se suceden y la amada no necesariamente será la misma.

Así, en "Innocence", sobre el reducido espacio de la cama se proyecta una fantasía cortesana, donde la amada es la reina rodeada de cortesanas y la amante es el bufón: "Manita's the Queen. Love and Love / lying by her, one / on each side" (Broumas 1977: 57). Las manos de la Reina se hunden en las "cuevas plegables" de Amor y Amor ("each hand so Deep / in Loves' collapsible caves") mientras el bufón rinde tributo a la Reina con su lengua afilada. En su primera traducción, publicada en Diario de Poesía, Bellessi traduce a las amantes secundarias en masculino, como si se tratara de una metáfora: "Manita es la Reina. Amor y Amor /

Revista Zona Franca- Centro de estudios interdisciplinario sobre las mujeres (CEIM)- Maestría poder y sociedad desde la problemática de género (MG), Rosario, Argentina. ISSN, 2545-6504 http://zonafranca.unr.edu.ar/index.php/ZonaFranca| Número 28 (2020). 
tendidos junto a ella, uno de cada lado" (27), y las "cuevas" de las otras dos amantes se convierten en "las cuevas plegables del amor". Esta interpretación más bien casta del poema de Broumas tal vez provenga de la costumbre de enlazar líricamente el yo y el tú en la estructura del amor romántico exclusivo VIII. No obstante, en la última versión de este poema, publicada en la reedición de Contéstame, baila mi danza (2019), Bellessi modifica la lectura: "Amor y amor / tendidas junto a ella, una / de cada lado", las manos se hunden "en las cuevas plegables de Amor y Amor" (599).

La lectura, la traducción, la cita, el erotismo, son algunos de los territorios de la poesía donde es posible abandonar parcialmente el yo y entrar en relación con lo otro. La suma de estas exploraciones en la poesía erótica y lesbiana se profundizan y se expanden en la propia escritura de Bellessi con la aparición de Eroica. Los poemas de Marichiko y de Olga Broumas anticipan este libro y seguramente hayan acompañado el proceso de escritura de Bellessi. No obstante, Bellessi complejiza ese instante de relación y comunión armoniosa a través del sexo que se ejemplifica en este poema de Marichiko:

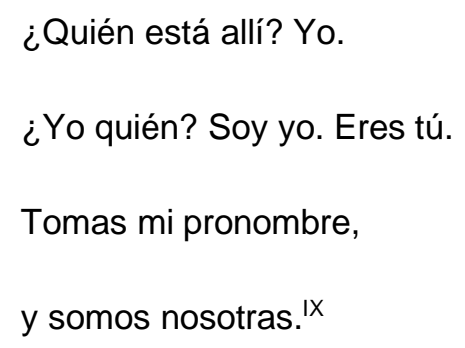

En Bellessi, en cambio, el erotismo es un campo de alteridad radical donde se deviene fiera y fantasma, y donde la constitución del yo a partir del tú, de lo propio a partir de lo ajeno, se da en una lucha donde hay trampas y juegos. Eroica busca

VIII Tal como señala Patricia Willson, el cotejo no sirve para señalar rasgos de traducciones particulares como errores, sino como "herramienta crítica y no prescriptiva; debería servir para ver, en las omisiones, agregados y paráfrasis, entre otros elementos, concepciones de la traducción, de la literatura, del lector, de la lengua de traducción" (2019: 26).

IX "Who is there? Me / Me who? I am me. You are you. / You take my pronoun, / and we are us" (Rexroth 2004: 721).

Revista Zona Franca- Centro de estudios interdisciplinario sobre las mujeres (CEIM)- Maestría poder y sociedad desde la problemática de género (MG), Rosario, Argentina. ISSN, 2545-6504 http://zonafranca.unr.edu.ar/index.php/ZonaFranca| Número 28 (2020). 
develar y deslindar espacios de dominación y liberación, y en ese sentido el cuerpo se convierte en un campo de lucha política no solo personal, sino también colectiva, ya que es en el cuerpo donde Bellessi logra vincular "de inmediato, en un ademán único, la borradura del habla femenina con el silenciamiento de la voz popular" (Monteleone 2009: 14).

En la primera parte de Eroica la primera persona prácticamente desaparece y deja lugar a la experiencia de un cuerpo en fusión con otros cuerpos. El "adormilado dedo adentro / del silencio / vivo" (2009: 323), la lengua, "pequeño animal morado / en succión que comba" (322), el ojo que "no quiere mirar / quiere tocar" (328). cuerpo es el cerco que separa de Ixs otrxs y al mismo tiempo punto de encuentro, condición de su propio quiebre "que inventa / la gracia imposible / del otro / Convexo / espejo de plata" (327). Así, esta gesta eroica no es tanto la replicación del gesto del héroe que penetra y conquista un territorio para constituir su subjetividad (Mallol, 2013:); si hay heroína, esta se constituye en el juego de disolución y diferenciación con la segunda persona, encarnada en la amante o en "el cuerpo común" del Pueblo: "en mitad del texto / el Pueblo / extiende su gesto" (330), e irrumpe la imagen palpitante la de la murga como momento colectivo y popular del cuerpo, que entre bombos y requiebres conjura "el Terror del golpe" (331) a través de las máscaras y las inversiones carnavalescas, "expulsión del otro encerrado en mí" (332).

Así, el yo va surgiendo lentamente como una subjetividad que se vuelve a forjar a sí misma través de la experimentación y la fricción con la Otra y con el Pueblo. Eroica inventa un espacio abierto, al que siempre se está entrando y donde siempre se deviene otra, en una "utopía del habla" que se ubica fuera de la ley a través de una experimentación verbal "muchas veces radicalizada, porque en ello va la autonomía de un decir, la inscripción de un deseo divergente de los patrones patriarcales o de las oposiciones cristalizadas del género" (Monteleone 2009:13).

En estas travesías, la traducción desempeña una función doble: hacia adentro, la constitución de un espacio de diálogo en la propia escritura; hacia afuera, la

Revista Zona Franca- Centro de estudios interdisciplinario sobre las mujeres (CEIM)- Maestría poder y sociedad desde la problemática de género (MG), Rosario, Argentina. ISSN, 2545-6504 http://zonafranca.unr.edu.ar/index.php/ZonaFranca| Número 28 (2020). 
creación pionera de una comarca de voces compañeras. Junto a ellas, Bellessi logra romper el silencio y hacer resurgir su propia voz, que en la década del ochenta no dejará de expandirse y establecer redes. No se trata tanto de crear un linaje, la línea paterna de ascendencia y descendencia, con las jerarquías que impone la temporalidad lineal, sino más bien de crear una red de parentescos raros (Haraway 2019: 31), una familia escogida desde la cual poder, nuevamente, empezar.

\section{Bibliografía}

BALDERSTON, Daniel (2011) "Never Say I": Inscriptions and Erasures of the Self in Queer Poetry in Spanish and Portuguese. A Contracorriente, 9 (1). Disponible en: http://d-scholarship.pitt.edu/10468/ (última consulta 7 de noviembre de 2020).

BELLESSI, Diana (1975). "Las mujeres de Stan Metal Corporation". Crisis, Nº 75.

---. (1986) “Escrituras eróticas”. En Diario de poesía № 2, pp. 26-27.

---. (1988) "Rexroth: poeta, traductor, falsificador". En Diario de poesía N 6 , pp. 28-29.

---. (1996) Lo propio y lo ajeno, Feminaria, Buenos Aires.

---. (2009) Tener lo que se tiene, Adriana Hidalgo, Buenos Aires.

---. (2011) La pequeña voz del mundo, Taurus, Buenos Aires.

---. (2017) "Delta del Paraná, febrero de 2009", "Buenos Aires, diciembre de 2010", "Retratos en la antesala", "Género y traducción" y "La cabra vuelve al monte". En La piedra es el poema, Espacio Hudson, Rada Tilly.

--- 2019. Contéstame, baila mi danza, Salta el Pez, Buenos Aires.

BRADBURY, Steve (2003). "Reading Rexroth Rewriting $\mathrm{Tu} F u$ in the 'Permanent War'". Jacket $\mathrm{N}^{\circ}$ 23, agosto de 2003. Disponible en: http://jacketmagazine.com/23/rex-brad.html (última consulta 7 de noviembre de 2020).

BROUMAS, Olga. (1999) Rave. Poems 1975-1999. Copper Canyon Press, Washington.

Revista Zona Franca- Centro de estudios interdisciplinario sobre las mujeres (CEIM)- Maestría poder y sociedad desde la problemática de género (MG), Rosario, Argentina. ISSN, 2545-6504 http://zonafranca.unr.edu.ar/index.php/ZonaFranca| Número 28 (2020). 
CARESANI, Rodrigo (2015). "Viaje y traducción en el fin de siglo latinoamericano". Revista Letral, №14. Disponible en; https://digibug.ugr.es/handle/10481/59130

FRANCESE, Francisco Álvez (2017). "Lo pequeño y lo infinito", EN La diaria, 5 de octubre. Disponible en https://ladiaria.com.uy/articulo/2017/10/lo-pequeno-y-loinfinito/ (última consulta 7 de noviembre de 2020).

CHUNG, Ling y Kenneth Rexroth (1972). The Orchid Boat. Women poets of China. New Directions, Washington.

GENOVESE, Alicia (2015). La doble voz: poetas argentinas contemporáneas Eduvim, Villa María.

HARAWAY, Donna (2019). Seguir con el problema. Generar parentesco en el Chthuluceno, Consonni, Buenos Aires.

MALLOL, Anahí (2013). "Mirta Rosenberg, Diana Bellessi: Poetas y traductoras" [en línea]. III Jornadas del Centro Interdisciplinario de Investigaciones en Género, 25, 26 y 27 de septiembre de 2013, La Plata, Argentina. Desde Cecilia Grierson hasta los debates actuales. En Memoria Académica. Disponible en: http://www.memoria.fahce.unlp.edu.ar/trab_eventos/ev.3444/ev.3444.pdf

MELCHIORRE, Valeria (2020). "Diana Bellessi: la voz de lo amado" Cahiers de LI.RI.CO, № 3. Disponible en: http://journals.openedition.org/lirico/790 (última consulta:7 de noviembre de 2020).

MONTELEONE, Jorge (2009). "La poesía como tierra sin mal: habla, mirada, gracia y donación" en Diana Bellessi, Tener lo que se tiene. Adriana Hidalgo, Buenos Aires, pp. 5-45.

MUSCHIETTI, Delfina (2003). "Todas las voces, todas". Radar Libros, Página/12, 13 de julio de 2003. Disponible en: https://www.pagina12.com.ar/diario/suplementos/libros/10-645-2003-07-13.html (última consulta 7 de noviembre de 2020).

PANESI, Jorge (2000). "La traducción en Argentina", en Críticas. Buenos Aires: Norma.

Revista Zona Franca- Centro de estudios interdisciplinario sobre las mujeres (CEIM)- Maestría poder y sociedad desde la problemática de género (MG), Rosario, Argentina. ISSN, 2545-6504 http://zonafranca.unr.edu.ar/index.php/ZonaFrancal Número 28 (2020). 
POLLOCK, Griselda. (2002) "Disparar sobre el canon. Acerca de cánones y guerras culturales", en Mora, Facultad de Filosofía y Letras, Universidad de Buenos Aires, N 8. [Trad. Laura Malosetti Costa]

REXROTH, Kennet (2004). The complete poems of Kenneth Rexroth. Washington: Copper Canyon Press.

SZENDY, Peter (2003). Escucha. Una historia del oído melómano. Barcelona, Paidós.

WILLSON, Patricia (2004). La Constelación del Sur, Siglo XXI, Buenos Aires.

---. (2019) "La crítica y la traducción como versiones de lo foráneo" y "Traducción entre siglos: un proyecto nacional", en Página impar. Textos sobre la traducción en Argentina: conceptos, historias, figuras. EThos Traductora, Buenos Aires.

YBAÑEZ, Roxana (2019). "Paisaje, poesía y voz en Tributo del mudo de Diana Bellessi”, en Recial Vol. X, $\mathrm{N}^{\circ} 15$, junio de 2019. Disponible en: https://revistas.unc.edu.ar/index.php/recial/article/view/24848 (última consulta 7 de noviembre de 2020).

Revista Zona Franca- Centro de estudios interdisciplinario sobre las mujeres (CEIM)- Maestría poder y sociedad desde la problemática de género (MG), Rosario, Argentina. ISSN, 2545-6504 http://zonafranca.unr.edu.ar/index.php/ZonaFrancal Número 28 (2020). 